\title{
Optimization of palm oil extraction from decanter cake using Soxhlet extraction and effects of microwaves pre-treatment on extraction yield and physicochemical properties of palm oil
}

\author{
${ }^{1}$ Ong, T.H., ${ }^{1,2 *}$ Hamzah, M.H. and ${ }^{1,2}$ Che Man, H. \\ ${ }^{I}$ Department of Biological and Agricultural Engineering, Faculty of Engineering, Universiti Putra \\ Malaysia, 43400 UPM Serdang, Selangor, Malaysia. \\ ${ }^{2}$ Smart Farming Technology Research Centre, Faculty of Engineering, Universiti Putra Malaysia, 43400 \\ UPM Serdang, Selangor, Malaysia.
}

\section{Article history:}

Received: 1 April 2020

Received in revised form: 18 August 2020

Accepted: 22 August 2020

Available Online: 3 January 2021

\section{Keywords:}

Soxhlet,

Palm oil,

Microwave,

Pre-treatment,

Extraction.

\section{DOI:}

https://doi.org/10.26656/fr.2017.5(S1).008

\begin{abstract}
Response Surface Methodology (RSM) was applied to study the optimum condition of palm oil extraction from oil palm decanter cake (OPDC) using Soxhlet extraction and nhexane as solvent. The main objective of this study was to achieve maximum oil extraction by determining the optimum of two parameters such as reaction time and solid to solvent ratio. The optimum parameters were found to be at $4.92 \mathrm{hrs}$ of reaction time and solid to solvent ratio of $1: 10$. The proposed model shows $\mathrm{R}^{2}$ value of 0.78 where the experimental parameters were significant to the result. The optimized data was employed for comparison of oil yield for OPDC without and with microwave pre-treatment. OPDC with microwave pre-treatment yielded $3.289 \pm 0.047 \mathrm{~g}$ of palm oil which was higher than OPDC without microwave pre-treatment which yielded only $3.107 \pm 0.085 \mathrm{~g}$ of palm oil. Fourier Transform Infrared Spectroscopy (FTIR) analysis also revealed the abundance of $\mathrm{C}-\mathrm{H}$ alkene stretch and $\mathrm{C}=\mathrm{O}$ stretch, two major functional groups indicated the presence of fatty acid within the palm oil derived from both samples. Scanning electron microscopy (SEM) of decanter cake provided evidence that the OPDC with pre-treatment has more shrinkage on the surface after Soxhlet extraction compared to OPDC without pretreatment. Results of this study revealed that RSM helps to optimize parameters in agricultural processing.
\end{abstract}

\section{Introduction}

Oil palm sector is one of the most major industries in Malaysia. Malaysia is the world second largest palm oil exporter in 2016 after Indonesia where the main export market in India with an intake of 2.83 million tonnes or $17.6 \%$ of total palm oil export (Kushairi, 2017). Aside from being one of the largest palm oil producers, Malaysia also generated a profusion amount of industrial waste (Liew et al., 2014). The estimated generated waste from every ton of fresh fruit bunch (FFB) is at the range from 0.6 to $0.8 \mathrm{~m}^{3}$ of palm oil mill effluent (POME), 22 to $23 \%$ of empty fruit bunch (EFB), $13.5 \%$ of palm mesocarp fibre (PMF) and $4-5 \%$ of oil palm decanter cake (OPDC) from a typical palm oil mill (Sahad et al., 2014).

Environmental issues are being concerned greatly in Malaysia as the palm oil mill contributed much on environmental pollution from its waste such as oil palm decanter cake (OPDC). The huge amount of OPDC production requires a large land area for composting and this will cause pollution hazards such as soil and water pollution (Farhana, 2010). Moreover, high production of biomass waste has negatively affected the total oil extraction rate (OER) of palm oil industry due to the losses of oil in the waste (Sahad et al., 2014). The OER indicates the actual amount of oils extracted from FFB, as well as the overall efficiency of typical palm oil mills. Hence approaches should be done to convert these biomass waste into another form of energy or usage. The current biomass residues are being used as fuel in the boiler or be converted into fertilizer. The solid biomass wastes are being used as the main source of energy input for few palm oil mills to produce electricity and steam for palm oil production process such as sterilizer ( $\mathrm{Wu}$ et al., 2017). Few researchers have studied the suitability of OPDC as ruminant feed, plant fertilizer and composting material (Bakri, 2013; Sahad et al., 2014). In addition, 
demand for biodiesel sector is increasing steadily (Szulczyk and Atiqur, 2018). Biodiesel is a renewable vehicle fuel based on biomass. Research showed that palm oil can be use as biodiesel for the vehicle with a diesel engine (Archer et al., 2018).

In this preliminary study, Soxhlet extraction was a conventional method used in the process of recovering phenolic compounds from the plant matrix. Soxhlet extraction is the most commonly used method for extracting phenolic compounds as this extraction method has various advantages such as low processing cost; simple operation; high performance; favourable for the total recovery of extracts and less time and solvent consuming (Alara et al., 2018). The soxhlet extraction method was used in this study to recover oil from OPDC. Hexane has high oil extraction efficiency, over 99\% hence it is widely used in the vegetable oil industry. Vegetable oils are produced from oilseeds through solvent extraction such as hexane or a combination of mechanical processing and solvent extraction (Pirshahid et al., 2018). A pre-treatment of microwave heating prior to Soxhlet extraction was also studied. A non-contact energy transfer process from electromagnetic energy into thermal energy occurred through microwave heating. If the electromagnetic energy is efficiently absorbed by the sample, the heating rate is increased. Based on the study by Sadeghi et al. (2017), changes in the cell structure of sample occurs which caused by electromagnetic waves, thus it affected the overall efficiency of the extraction process.

The objectives of this study were to study the optimization of palm oil extraction from decanter cake by Soxhlet extraction using Response Surface
Methodology and to compare the performance of microwave pre-treatment prior to Soxhlet extraction in terms of the oil yield, chemical, physical and surface morphology of OPDC.

\section{Materials and methods}

\subsection{Summary of Experimental Flow}

The overall flow chart of the methodology was presented in Figure 1.

\subsection{Sample Preparation}

Oil palm decanter cake (OPDC) was collected from Jengka Pahang Palm Oil Mill and kept in the cold storage room at $5^{\circ} \mathrm{C}$. n-Hexane (J.T.Baker ${ }^{\mathrm{TM}}$, United States) was used as the solvent. All chemicals used in this study were of analytical grade.

\subsection{Experimental design}

The optimized data of the following parameters were analysed using RSM: (A, reaction time, 4-8 hrs) and (B, solvent ratio, 10-13) also the affected response variable (Y, yield of oil extracted). The $\alpha$ value represented the distance of each star point from the centre, was set to 1.5 $(\alpha=1.5)$. Central composite design (CCD) was used for thirteen randomized experiments (8 non-centre points and 5 centre points) to develop a response surface that determines the optimal variables A and B that resulted in the highest response variable $\mathrm{Y}$ as shown in Table 1 . The experiment was conducted in triplicate to obtain the average value of $Y$. The average oil yield data was keyed in the Design Expert Version 11 software, the optimization process was started. For optimized data, the software was set up to generate the minimum reaction

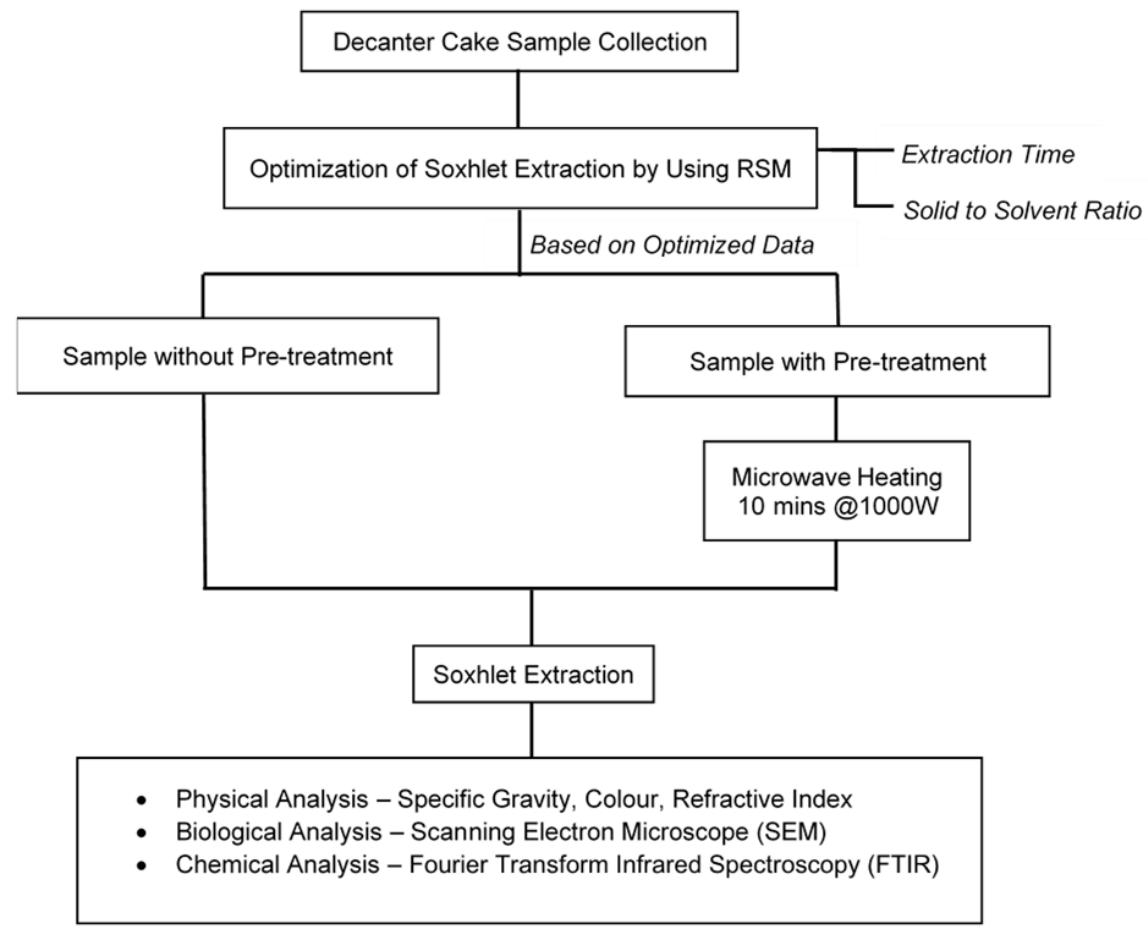

Figure 1. Flow chart of palm oil extraction from OPDC. 
time, minimum solvent ratio and maximize yield of oil extract to achieve the 3 criteria as shown in Table 1. The chosen optimized data with the highest desirability was tested by carrying out another experiment to confirm the oil yield. Table 1 shows the criteria set up to obtain the optimized data.

Table 1. Experimental parameters for CCD of Soxhlet extraction.

\begin{tabular}{ccccc}
\hline \multirow{2}{*}{ Factors } & \multirow{2}{*}{ Parameters } & \multicolumn{2}{c}{ Limits } & \multirow{2}{*}{ Criteria } \\
\cline { 3 - 4 } & & Lower & Upper & Minimum \\
A & Reaction time & 4 & 8 & Mimum \\
B & Solvent ratio & 10 & 13 & Minimum \\
Y & $\begin{array}{c}\text { Yield of oil } \\
\text { extracted }\end{array}$ & 2.787 & 3.664 & Maximum \\
\hline
\end{tabular}

\subsection{Soxhlet Extraction}

About $45 \mathrm{~g}$ of OPDC was measured by using an electronic balance (SHIMADZU Electronic Balance TX223, Japan) then moulded in a uniform rectangular cube. The sample was then dried in oven dryer (MEMMERT Universal Oven UN55, Germany) at $105^{\circ} \mathrm{C}$ for $24 \mathrm{hrs}$. A total of $20 \mathrm{~g}$ of dried OPDC was weighted and crushed into smaller pieces with a hammer and placed in a cellulose extraction thimble (CT30100, AquaLab Supplies, Spain) with internal diameter and length $(30 \times 100 \mathrm{~mm})$. The thimble was then filled with cotton as a stopper to prevent OPDC from leaking out during extraction. The amount of solvent used is based on the experimental data shown on Table 2 and the solvent was measured and filled into a bottom flask. The amount of solid used is fixed which is $20 \mathrm{~g}$ and the solid to solvent ratio is $(1: \mathrm{x})$ where $\mathrm{x}$ indicated the solvent ratio. The calculation of the amount of solvent used is calculated by using Equation 1:

Amount of solvent used $(\mathrm{ml})=20 \mathrm{~g} \times$ solvent ratio

The temperature of Soxhlet extractor (JEX5/55 FAVORIT, Malaysia) was set to 3 for pre-heating and later changed to 4 (approximately $70^{\circ} \mathrm{C}$ ). A total of six experiments were carried out following the experimental

Table 2. Experimental result

\begin{tabular}{cccc}
\hline & Factor 1 & Factor 2 & Response \\
\cline { 2 - 4 } Run & A: Reaction Time & B: Solvent Ratio & Yield of extracted \\
\hline 1 & 6 & 11.25 & $3.334 \pm 0.25$ \\
2 & 3 & 11.25 & $2.787 \pm 0.21$ \\
3 & 6 & 11.25 & $3.082 \pm 0.05$ \\
4 & 6 & 11.25 & $3.037 \pm 0.12$ \\
5 & 4 & 12.5 & $2.991 \pm 0.17$ \\
6 & 6 & 11.25 & $3.025 \pm 0.11$ \\
7 & 4 & 10 & $3.006 \pm 0.14$ \\
8 & 8 & 11.25 & $3.286 \pm 0.26$ \\
9 & 6 & 10 & $3.298 \pm 0.19$ \\
10 & 6 & 11.25 & $3.064 \pm 0.07$ \\
11 & 8 & 12.5 & $3.328 \pm 0.06$ \\
12 & 8 & 10 & $3.314 \pm 0.23$ \\
13 & 6 & 13 & $3.644 \pm 0.06$ \\
\hline
\end{tabular}

eISSN: 2550-2166 setup and shown in Table 2. Meanwhile, the solvent was separated from the oil using rotary vacuum evaporator (Heidolph Laborota 4000, Germany) and was collected in the receiving flask. All experiments were performed in triplicate. The amount of extracted oil was weighed and recorded.

\subsection{Sample pre-treatment}

Another experiment was carried out by using the optimized data of Soxhlet extraction for factor A and B. Microwave oven (Panasonic Microwave Oven NN-J993, Japan) was used for this experiment. Dried OPDC underwent microwave heating for 10 mins at $1000 \mathrm{~W}$ following the method proposed by (Xern, 2017) as pretreatment. After heating, $20 \mathrm{~g}$ of dried OPDC was used for Soxhlet extraction by using the optimized data from RSM (reaction time, $4.9 \mathrm{hrs}$ and solvent ratio, 10). The amount of extracted oil from the sample with and without pre-treatment was compared and discussed.

\subsection{Physical analysis}

Physical analysis on extracted oil for the sample with and without pre-treatment was determined. The specific gravity of the samples was calculated following Equation 2 by measuring the mass of oil sample using an electronic balance (SHIMADZU Electronic Balance TX223, Japan) and volume of oil sample using $100 \mathrm{~mL}$ measuring cylinder, colour measured by using colour reader (Konica Minolta Colour Reader Cr-10, Japan) while the refractive index was measured by using a refractometer (KRUSS Digital ABBE Refractometer AR2008, Germany). The temperature of oil samples was maintained at $50^{\circ} \mathrm{C}$ where the results were later compared with the references of standard values (Koushki and Nahidi, 2008; Chinedu and Ebere, 2017).

$$
\text { Specific gravity }=\frac{\text { (mass of oil sample }) /(\text { volume of oil sample })}{\text { density of water }}
$$

\subsection{Chemical analysis}

Chemical analysis of extracted palm oil samples without special pre-treatment was carried out by using Fourier Transform Infrared Spectroscopy (FTIRSpectrum 100 JASCO, Japan). The IR spectra were determined over a wavenumber range from 4000 to 650 $\mathrm{cm}^{-1}$. The resolution was $4 \mathrm{~cm}^{-1}$ and 32 scans were averaged. FTIR is used to determine the functional group components from 2 extracted palm oil samples which were palm oil extracted from sample with and without pre-treatment. The $\mathrm{pH}$ value of oil samples was measured by using a $\mathrm{pH}$ meter.

\subsection{Biological analysis}

Biological analysis was carried out on OPDC 
without pre-treatment and OPDC sample with pretreatment by using Scanning Electron Microscope (SEM) (SEM S-3400N Hitachi, Japan) where the SEM images at 300x magnification of the samples was taken digitally. Each sample was coated with a layer of gold for $120 \mathrm{~s}$ using a coater (Quorumtech EMscope SC500 Sputter Coater, United Kingdom). Images of 4 OPDC samples were captured: OPDC after oven dry; OPDC after Soxhlet extraction (without pre-treatment); OPDC after microwave pre-treatment; and OPDC after Soxhlet extraction (with pre-treatment).

\section{Results and discussion}

\subsection{Sample without pre-treatment}

The thirteen experiment runs were designed by RSM software where the response, yield of extracted oil was measured and recorded as shown on Table 2. Increasing solvent ratio causes the increment of the concentration gradient between the solid and the liquid phase where it favours good mass transfer thus higher yield of oil extracted (Sayyar et al., 2009). A longer reaction time enhanced the diffusion process of oil in solvent which resulted in higher oil yield. As depicted in Table 2, the least yield of oil extracted $(2.787 \mathrm{~mL})$ was on experiment run 2 at $3 \mathrm{hrs}$ of reaction time and the solvent ratio of $1: 11.25$, meanwhile the highest yield of oil extracted (3.644 mL) was on an experiment run 13 with $6 \mathrm{hrs}$ of reaction time and solvent ratio of 1:13.

\subsection{Data optimization by using RSM}

Figure 2 shows the 3D surface plot for the yield of oil extract before optimization. The response surface plot showed the optimal condition between the variables such as reaction time and solvent ratio (Pirshahid et al., 2018). The red dots on the 3D plot showed the data above the predicted value while the pink dots showed data below the predicted value. Figure 2(a) showed that the highest point on the 3D plot is below the expected value, hence an optimization was carried out and resulted in a more uniform 3D plot as shown in Figure 2(b). The optimized response surface plot as shown in Figure 2(b) revealed the increased oil yield with increasing variables $A$ and $B$.
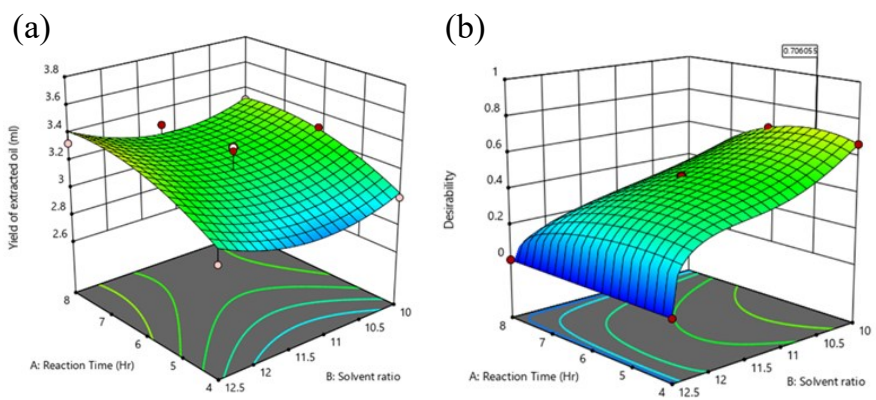

Figure 2. 3D response surface plot, (a) response surface plot before optimization, (b) response surface plot after optimization
There was a total of 10 solutions generated following the criteria set up where only solution with the highest desirability to achieve the criteria will be chosen to carry out a confirmation test on oil yield. The chosen solution with 0.706 desirability was at $4.923 \mathrm{hrs}$ of reaction time and the solvent ratio of 10 which is $200 \mathrm{~mL}$. The expected oil yield should be $3.179 \mathrm{~mL}$. To verify the yield, 3 confirmation tests were carried out based on the parameters in the chosen solution that achieved the criteria which were lowest reaction time and lowest ratio that gives the highest oil yield. Based on the confirmation test, the average oil yield based on the chosen solution was $3.107 \pm 0.085 \mathrm{~mL}$ where it is lower than the expected oil yield $(3.179 \mathrm{~mL})$. The difference between theoretical oil yield and experimental oil yield was $0.072 \mathrm{~mL}$. The percent error is considered low which is $2.26 \%$ as the desirability to achieve the criteria was $0.706(70.6 \%)$.

\subsection{Statistical analysis}

A statistical analysis of variance (ANOVA) is performed to see either the process parameters are statistically significant which is shown in Table 3 . Finally, a confirmation test is conducted to verify the optimal process parameters obtained from the process parameter design.

Based on Table 3, the Model F-value of 4.84 implies the model is significant. There is only a $3.11 \%$ chance that an F-value this large could occur due to noise. Parameter A has the highest $F$ value (7.77), hence it has the most influence in oil extraction process. P-values less than 0.05 indicate model terms are significant (Mushtaq et al., 2015). In this case $\mathrm{A}, \mathrm{B}^{2}$ are significant model terms. Values greater than 0.05 indicates the model terms are not significant. Based on Table 2, B showed p-value greater than 0.05 which is not significant. The Lack of Fit F-value of 0.72 implies the Lack of Fit is not significant relative to the pure error. There is a $58.99 \%$ chance that a Lack of Fit F-value this large could occur due to noise. Non-significant lack of fit is good so that a fit model is obtained.

Table 3 shows the fit statistics analysis for the experimental run. R-squared is a statistical measure of how close the data are to the fitted regression line. $\mathrm{R}^{2}$ approaching 1 showed the model is completely fit while $\mathrm{R}^{2}$ approaching 0 showed that the model cannot be used due to large variance differences (Drennan, 1996). The predicted $\mathrm{R}^{2}$ of 0.0561 is not as close to the adjusted $\mathrm{R}^{2}$ of 0.6156 as one might normally expect; i.e. the difference is more than 0.2. This may indicate a large block effect or a possible problem with the model and/or data. Things to consider are model reduction, response transformation, outliers, etc. All empirical models should 
Table 3. ANOVA Test for Response 1(Y): Yield of Extracted Oil

\begin{tabular}{|c|c|c|c|c|c|c|}
\hline Source & Sum of Squares & $\mathrm{df}$ & Mean Square & F-value & p-value & \\
\hline Model & 0.455 & 5 & 0.091 & 4.84 & 0.0311 & significant \\
\hline A-Reaction Time & 0.1461 & 1 & 0.1461 & 7.77 & 0.027 & \\
\hline B-Solvent ratio & 0.0094 & 1 & 0.0094 & 0.4981 & 0.5031 & \\
\hline $\mathrm{AB}$ & 0.0002 & 1 & 0.0002 & 0.0112 & 0.9187 & \\
\hline $\mathrm{A}^{2}$ & 0.0581 & 1 & 0.0581 & 3.09 & 0.1221 & \\
\hline $\mathrm{B}^{2}$ & 0.1143 & 1 & 0.1143 & 6.08 & 0.043 & \\
\hline Residual & 0.1315 & 7 & 0.0188 & & & \\
\hline Lack of Fit & 0.0461 & 3 & 0.0154 & 0.7204 & 0.5899 & not significant \\
\hline Pure Error & 0.0854 & 4 & 0.0213 & & & \\
\hline Cor Total & 0.5865 & 12 & & & & \\
\hline Std. Dev. & 0.1371 & \multicolumn{2}{|r|}{$\mathrm{R}^{2}$} & 0.7758 & & \\
\hline Mean & 3.19 & \multicolumn{2}{|r|}{ Adjusted R ${ }^{2}$} & 0.6156 & & \\
\hline \multirow[t]{2}{*}{ C.V. \% } & \multirow[t]{2}{*}{4.3} & & Predicted $\mathrm{R}^{2}$ & 0.0561 & & \\
\hline & & & Adeq. Precision & 8.7604 & & \\
\hline
\end{tabular}

be tested by doing confirmation runs. Adeq. precision measures the signal to noise ratio. A ratio greater than 4 is desirable (Yang et al., 2018). The ratio of 8.760 indicates an adequate signal.

Figure 3 shows that the levels of the oil yield predicted from the fitted empirical model are in line agreed with the observed values under the observed experimental conditions, with a sensibly high value of the coefficient of determination of $0.7758\left(\mathrm{R}^{2}\right)$ (Table 3) (Mushtaq et al., 2015). The coloured dots showed the actual oil yield where the straight graph showed the predicted value. Based on Figure 3, there were few points fall below the expected value and a few points were above the predicted value. It shows the correlation between predicted and actual data are similar. The graph showed consistent data that proven this experiment data is acceptable.

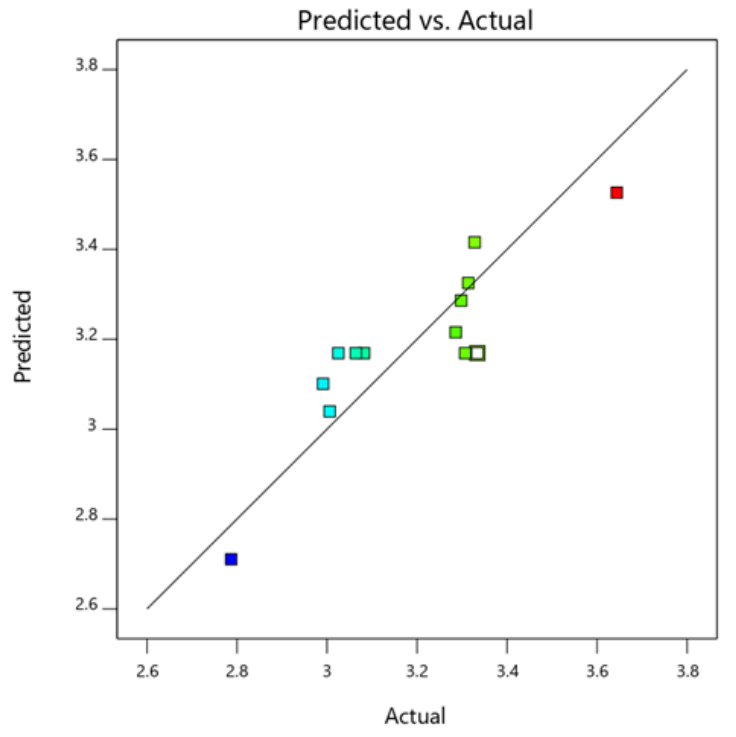

Figure 3. Graph of predicted vs actual value of oil yield

\subsection{Regression model equation}

The regression model equation generated by RSM to calculate the oil yield based on factors A and B with response $\mathrm{Y}$. The equation in terms of actual factors can be used to make predictions about the response $\mathrm{Y}$ for given levels of factors A and B. Here, the levels should be specified in the original units for each factor. The regression model Equation 3 is as follow:

Yield of extracted oil =

$+14.19407$

$+0.353781 \quad$ Reaction Time (A)

$-2.21912 \quad$ Solvent ratio (B)

$+0.002900 \quad$ Reaction Time * Solvent ratio

$-0.025944 \quad$ Reaction Time $^{2}$

$+0.099206 \quad$ Solvent ratio ${ }^{2}$

Yield of extracted oil $(\mathrm{mL})$

$=14.19407+0.353781(A)-2.21912(B)+0.0029(A * B)-0.025944\left(A^{2}\right)$ $+0.099206\left(B^{2}\right)$

\subsection{Data comparison between sample without and with pre-treatment}

The average oil yield for OPDC microwave pretreatment was $3.289 \pm 0.047 \mathrm{~g}$ at $4.923 \mathrm{hrs}$ of reaction time and the solvent ratio of $10(200 \mathrm{~mL})$ which was greater than OPDC sample without pre-treatment $3.107 \pm 0.085 \mathrm{~g}$ as shown in Figure 4. The difference between both yield value was $0.182 \mathrm{~g}$ or $5.533 \%$ more oil yield compare to sample without pre-treatment.

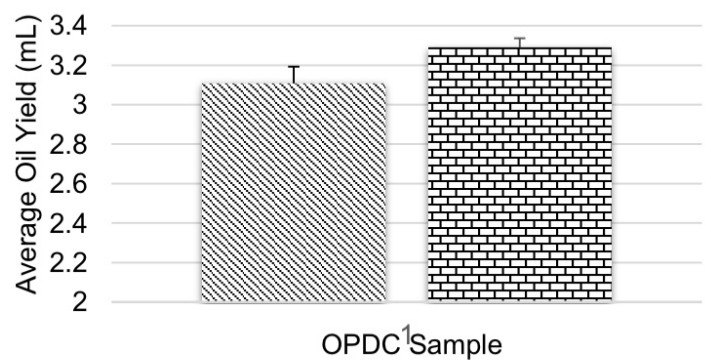

«Without Pre-treatment $\quad$ With Pre-treatment

Figure 4. Comparison of average oil yield for both sample 
Microwave pre-treatment is different compare to regular oven drying. Microwave heating used electromagnetic wave that heats throughout the OPDC sample while oven drying heats up OPDC sample from the outer surface only. Microwaves are a form of nonionizing electromagnetic energy emitting at frequencies ranging from $300 \mathrm{MHz}$ to $300 \mathrm{GHz}$ (Sadeghi et al., 2017). This energy transmitted as wave and penetrated through biomaterials as well as interacted with polar molecules of materials, such as water to generate heat. Microwaves acted directly on molecules by ionic conduction and dipole rotation and thus only polar materials can be heated based on their dielectric constant (Sadeghi et al., 2017).

\subsection{Physical analysis of extracted oil}

The physical properties (Specific gravity, colour and refractive index at $50^{\circ} \mathrm{C}$ ) of extracted oil from OPDC with microwave pre-treatment and without microwave pre-treatment were carried out and the results were shown in Table 4. The result was compared to the standard at $50^{\circ} \mathrm{C}$ (Koushki and Nahidi, 2008; Chinedu and Ebere, 2017). Specific Gravity (SG) is a term used to define the density or weight of a liquid as compared to the density of an equal volume of water at a specified temperature (Chinedu and Ebere, 2017). Based on Table 4 , the oil extracted from the sample without pretreatment has a higher density $\left(0.948 \mathrm{~g} / \mathrm{cm}^{3}\right)$ and SG value (0.960) compared to the sample with pretreatment. However, both oil samples had similar density and SG compared to standard.

Colour and appearance are important quality parameters for oil. Any colour within visible range was represented with the aid of three-dimensional coordinates $\mathrm{L}$, $\mathrm{a}$ and $\mathrm{b}$. Based on Table 4, both oil samples had similar L, a, b value. By referring to the CIELAB Colour
Chart (Paravina, 2018), the colour of the oil sample was light yellowish colour at $50^{\circ} \mathrm{C}$.

Table 4. Physical properties of palm oil based on standard at $50^{\circ} \mathrm{C}$.

\begin{tabular}{|c|c|c|c|c|}
\hline \multicolumn{2}{|c|}{$\begin{array}{l}\text { Physical } \\
\text { Characteristics }\end{array}$} & $\begin{array}{l}\text { Without } \\
\text { Pre- } \\
\text { treatment }\end{array}$ & $\begin{array}{l}\text { With Pre- } \\
\text { treatment }\end{array}$ & Standard value \\
\hline \multicolumn{2}{|c|}{ Density $\left(\mathrm{g} / \mathrm{cm}^{3}\right)$} & 0.948 & 0.886 & 0.889 \\
\hline \multicolumn{2}{|c|}{ Specific Gravity } & 0.96 & 0.897 & 0.906 \\
\hline & $\mathrm{L}$ & 58.8 & 58.7 & \\
\hline \multirow{2}{*}{ Colour } & $\mathrm{a}$ & 6 & 5.8 & nil* \\
\hline & $\mathrm{b}$ & 29.3 & 29 & \\
\hline \multicolumn{2}{|c|}{ Refractive Index (nd.) } & 1.462 & 1.462 & $1.455-1.462$ \\
\hline
\end{tabular}

${ }^{\#}$ Adapted from Koushki and Nahidi (2008), Chinedu and Ebere (2017)

*the colour result was not reported

Refractive index (RI) showed how much light bends when it travelled through the soil sample (Chinedu and Ebere, 2017). The value of RI for oil sample without and with pre-treatment is the same and similar compared to reference standard value.

\subsection{Chemical analysis of extracted oil}

The FTIR spectra of oil extracted for the sample without and with pre-treatment by Soxhlet extraction are presented in Figure 5. Overall, the results showed a relatively similar FTIR spectra pattern. The major finding of extracted oil at different processing routes is that the oil showed very similar peaks where the first peak at 2854 to $2925 \mathrm{~cm}^{-1}$ indicated the presence of C-H alkene stretch and a representative of specific fingerprint around $1745 \mathrm{~cm}^{-1}$ attributed to $\mathrm{C}=\mathrm{O}$ stretch which have similar reading compare to a study (Fauzi et al., 2016). The result strongly supports that the extracted oil contains ester. Both oil samples were measured to be acidic where oil sample with pre-treatment showed

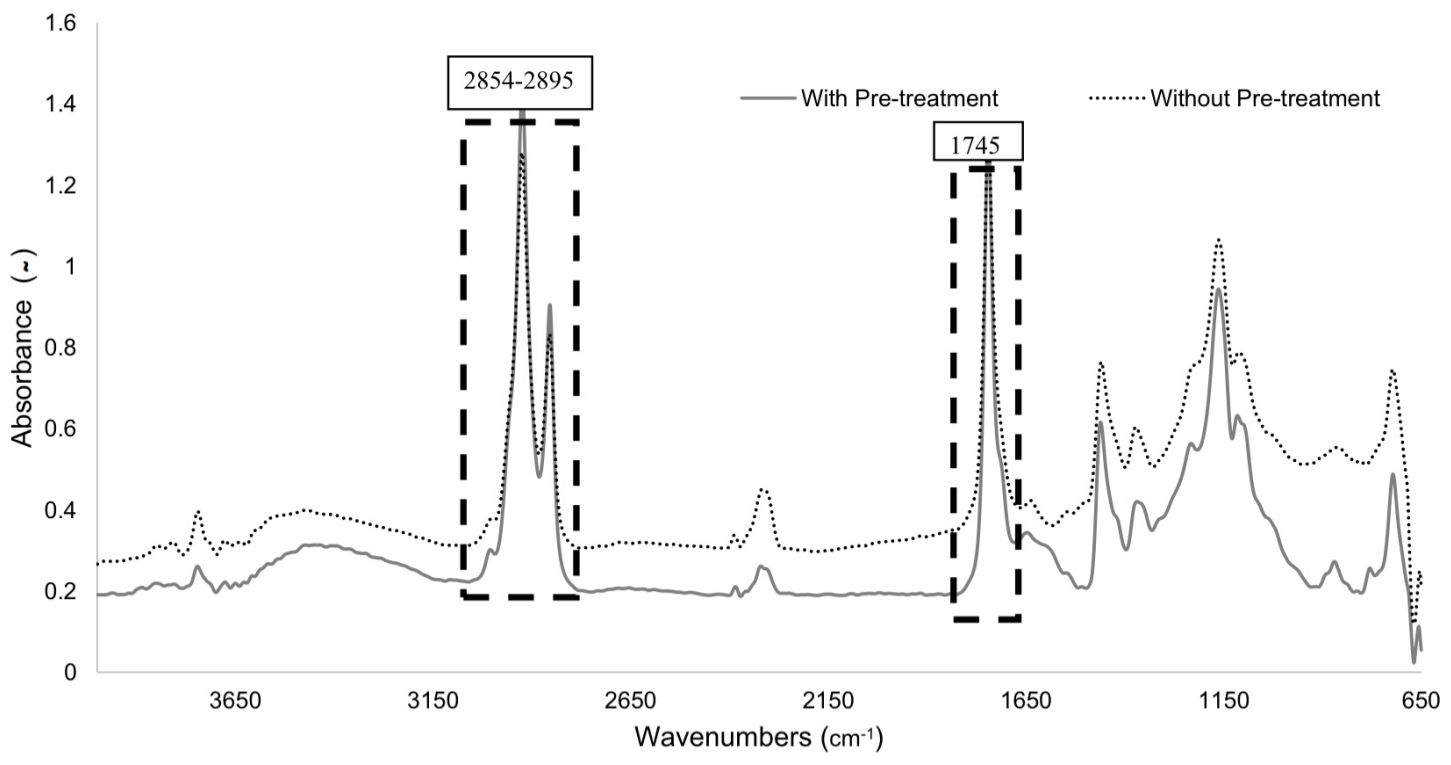

Figure 5. FTIR spectra of extracted oil samples. 
higher acidic ( $\mathrm{pH}$ 5.135) compared to oil extract without pre-treatment ( $\mathrm{pH}$ 5.690). This explained the absorbance of $1 \mathrm{st}$ peak for the sample with pre-treatment was observed to be much higher than that of the sample without pre-treatment.

Ester is derived from carboxylic acid and alcohol ester is the main class of lipids which makes up the vegetable oil. Both functional groups indicated the presence of fatty acid in the oil extract (Fauzi et al., 2016). Further analysis was suggested to be performed in future on oil extract by using Gas-chromatography to determine the component in oil extracts as palm oil contains oleic and palmitic acid the most which portray its oil quality.

\subsection{Biological analysis of OPDC samples}

The structure images of oil palm decanter (OPDC) samples were captured by using scanning electron microscope (SEM) as shown in Figure 6. Figure 6 (a-d) shows SEM images of OPDC without pre-treatment before Soxhlet extraction; OPDC without pre-treatment after Soxhlet extraction; OPDC with pre-treatment before Soxhlet extraction and OPDC with pre-treatment after Soxhlet extraction respectively.
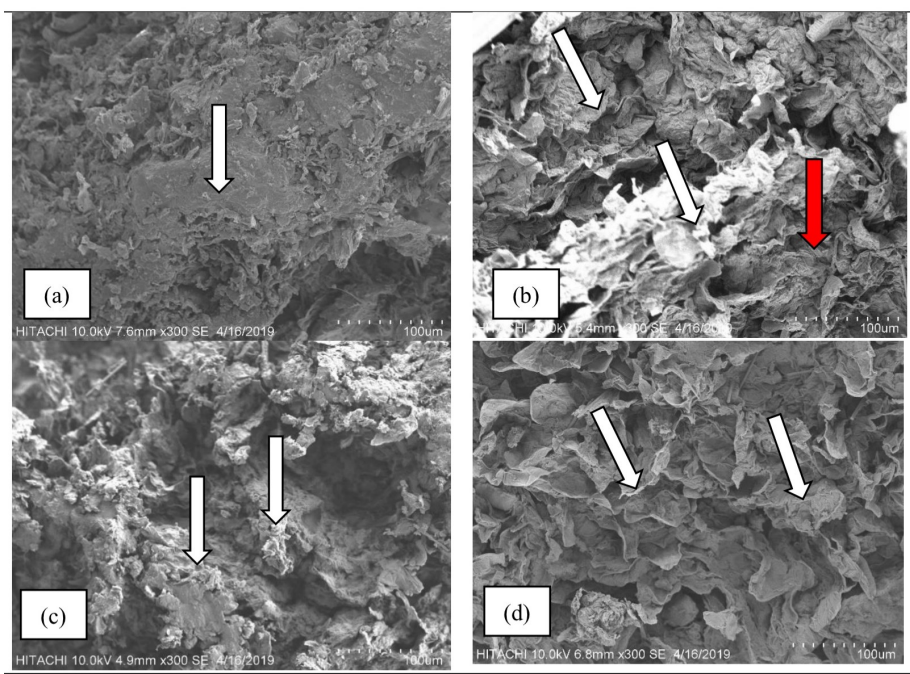

Figure 6. Scanning electron micrograph of OPDC; (a) SEM image of OPDC without pre-treatment before Soxhlet extraction; (b) SEM image of OPDC without pre-treatment after Soxhlet extraction; (c) SEM image of OPDC with pretreatment before Soxhlet extraction; (d) SEM image of OPDC with pre-treatment after Soxhlet extraction.

SEM images showed the morphological changes on the surface of the OPDC samples. The surface of OPDC sample without pre-treatment before extraction appear to be flatter and smoother as shown in Figure 6(a) compare to OPDC with microwave pre-treatment before Soxhlet extraction as shown in Figure 6(c) where the surface has started to shrink. OPDC sample treated by microwave heating resulted in more breakage of sacs that contains oil and it is proved where OPDC sample after microwave showed darker in colour and appear to be wet. A study by (Sadeghi et al., 2017) also stated electromagnetic waves changes the cell structure of the sample. For sample after Soxhlet extraction, Figure 6(b) image shows a red arrow where the labelled part is still smooth and flatten compare to Figure 6(d) as the overall surface shown to be more shrunk. This showed that more oil was extracted for OPDC with microwave pre-treatment compare to OPDC without pre-treatment as stated in the result of oil yield comparison in Figure 4. In contrast, OPDC sample shown shrunk surface as the oil was extracted from the sample.

\section{Conclusion}

Response Surface Methodology is a great tool for designing laboratory-scale experiment while providing statistical analysis to support the data. Optimization of palm oil extraction from decanter cake using Soxhlet extraction by RSM presented that at $4.923 \mathrm{hrs}$ of reaction time and solid to solvent ratio of 1:10 has the highest oil yield which is $3.107 \pm 0.085 \mathrm{~g}$. The proposed model design by RSM shows $\mathrm{R}^{2}$ value of 0.776 where the experimental parameters are significant to the result. OPDC sample with and without microwave pretreatment was compared and the results indicated microwave pre-treatment $(1000 \mathrm{~W}, 10 \mathrm{mins})$ yielded $3.289 \pm 0.085 \mathrm{~g}$ of palm oil which was higher than that of OPDC without microwave pre-treatment $(3.107 \pm 0.085$ g). Physical analysis of extracted oil from OPDC without and with microwave pre-treatment was carried out where both data were similar. Chemical analysis by using FTIR showed that both oil sample has two similar peaks on the FTIR Spectra where the $1^{\text {st }}$ peak at the range of 2854 to $2925 \mathrm{~cm}^{-1}$ indicated the present of $\mathrm{C}-\mathrm{H}$ alkene stretch and $2^{\text {nd }}$ peak at 1754 which was $\mathrm{C}=\mathrm{O}$ stretch ester. Both of these functional groups indicated the presence of fatty acid in the oil sample. Lastly, biological analysis with SEM images indicated that OPDC with pre-treatment had more shrinkage on the surface after Soxhlet extraction compared to OPDC without pre-treatment. The result proved that higher oil yield from OPDC with microwave pre-treatment.

\section{Acknowledgement}

This research was financially supported by Geran Putra - Inisiatif Putra Muda (GP-IPM) through Universiti Putra Malaysia Grant (Grant No: GPIPM/2018/9669700). The authors would like to acknowledge the financial support provided by Department of Biological and Agricultural Engineering, Faculty of Engineering, Universiti Putra Malaysia. 


\section{References}

Alara, O.R., Abdurahman, N.H. and Ukaegbu, C.I. (2018). Soxhlet extraction of phenolic compounds from Vernonia cinerea leaves and its antioxidant activity, Journal of Applied Research on Medicinal and Aromatic Plants, 11, 12-17. https:// doi.org/10.1016/j.jarmap.2018.07.003

Archer, S.A., Murphy, R.J. and Steinberger-Wilckens, R. (2018). Methodological analysis of palm oil biodiesel life cycle studies. Renewable and Sustainable Energy Reviews, 94, 697-704. https:// doi.org/10.1016/j.rser.2018.05.066

Bakri, M. (2013). Regenerate of decanter cake from palm oil mill waste effluent for the removal al of heavy metal ions from industrial wastewater. Malaysia: Universiti Teknikal Malaysia, BSc. Thesis

Chinedu, E.E. and Ebere, E.C. (2017). Quality assessment of palm oil from different palm oil local factories in Imo State, Nigeria. World Scientific News, 88(2), 152-167.

Drennan, D.R. (1996). Statistics for archaeologists, a common sense approach, p. 215. USA: Springer.

Farhana, S. (2010). To study the production viability of bio-briquette from oil palm decanter cake. Malaysia: Universiti Malaysia Pahang, BSc. Thesis.

Fauzi, A.A., Arsad, A., Zaini, M.A.A. and Md Yunus, M.A.B. (2016). Extraction of oil from filter cake sludge using soxhlet extraction. Journal of Engineering and Applied Sciences, 11(12), 25612565.

Koushki, M. and Nahidi, M. (2008). Physico-chemical properties, fatty acid profile and nutrition in palm oil, Journal of Paramedical Sciences, 6(3), 117-134.

Kushairi, A. (2017). Overview of the Malaysian oil palm industry 2016. Malaysia: Malaysian Palm Oil Board.

Liew, W.L., Kassim, M.A., Muda, K., Loh, S.K. and Affam, A.C. (2015). Conventional methods and emerging wastewater polishing technologies for palm oil mill effluent treatment: A review. Journal of Environmental Management, 149, 222-235. https://doi.org/10.1016/j.jenvman.2014.10.016

Mushtaq, M., Sultana, B., Bhatti, H.N. and Asghar, M. (2015). RSM based optimized enzyme-assisted extraction of antioxidant phenolics from underutilized watermelon (Citrullus lanatus Thunb.) rind. Journal of Food Science and Technology, 52 (8), 5048-5056. https://doi.org/10.1007/s13197-014$1562-9$

Paravina, R.D. (2018). Understanding color. In Goldstein, R.E., Chu, S.J., Lee, E.A., Stappert, C.F.J. (Eds). Ronald E. Goldstein's Esthetics in Dentistry. $3^{\text {rd }}$ ed., p. 270-294. United Kingdom: Wiley Online
Library.

https:// doi.org/10.1002/9781119272946.ch10

Pirshahid, S.A., Arirob, W. and Punsuvon, V. (2018). Optimization of palm oil extraction from Decanter cake of small crude palm oil mill by aqueous surfactant solution using RSM. IOP Conference Series: Materials Science and Engineering, 348, 012011. https://doi.org/10.1088/1757$899 X / 348 / 1 / 012011$

Sadeghi, A., Hakimzadeh, V. and Karimifar, B. (2017). Microwave assisted extraction of bioactive compounds from food: a review, International Journal of Food Science and Nutrition Engineering, 7(1), 19-27.

Sahad, N., Som, A.M., Baharuddin, A.S., Mokhtar, N., Busu, Z. and Sulaiman, A. (2014). Physicochemical characterization of oil palm decanter cake (OPDC) for residual oil recovery. BioResources, 9(4), 63616372. https://doi.org/10.15376/biores.9.4.6361-6372

Sayyar, S., Abidin, Z.Z., Yunus, R. and Muhammad, A. (2009). Extraction of oil from Jatropha seedsoptimization and kinetics. American Journal of Applied Sciences, 6(7), 1390-1395. https:// doi.org/10.3844/ajassp.2009.1390.1395

Szulczyk, K.R. and Atiqur Rahman Khan, M. (2018). The potential and environmental ramifications of palm biodiesel: evidence from Malaysia. Journal of Cleaner Production, 203, 260-272. https:// doi.org/10.1016/j.jclepro.2018.08.241

Wu, Q., Qiang, T.C., Zeng, G., Zhang, H., Huang, Y. and Wang, Y. (2017). Sustainable and renewable energy from biomass wastes in palm oil industry: A case study in Malaysia. International Journal of Hydrogen Energy, 42(37), 23871-23877. https:// doi.org/10.1016/j.ijhydene.2017.03.147

Xern, J.T.C. (2017). Production of crude palm oil through microwave pretreatment cum solvent extraction. Malaysia: Universiti Malaya, MSc. Thesis.

Yang, L., Wang, L., Gao, J., Guo, S., Ye, X., Koppala, S., Hu, T., Hou, M. and Hu, Lo. (2018). Optimization of process parameters for preparing metallic matrix diamond tool bits by microwave pressureless sintering using response surface methodology. Materials, 11(11), 2815. https:// doi.org/10.3390/ma11112185 